\title{
POTENCIAL DE UTILIZAÇÃO DE EFLUENTES TRATADOS DE LATICÍNIOS
}

UTILIZATION POTENTIAL OF TREATED WASTEWATER FROM DAIRY

\section{Taryane Augusta Fernandes}

Engenheira Ambiental pela

Universidade Federal do Tocantins

(UFT) - Palmas (TO), Brasil.

\section{Liliana Pena Naval}

Doutora em Engenharia Química pelo Universidad Complutense de Madrid (UCM). Docente da Fundação Universidade Federal do Tocantins (UFT) - Palmas (TO), Brasil.

\section{Endereço para correspondência:} Liliana Pena Naval - Avenida NS 15, 109 Norte, Bloco 2, Sala 7 Plano Diretor Norte - 77001-090 Palmas (TO), Brasil -

E-mail: liliana@mail.uft.edu.br

Recebido: $13 / 02 / 2017$

Aceito: 13/11/2017

\section{RESUMO}

A utilização de águas de reúso nas indústrias vem se tornando uma opção viável para reduzir o lançamento de efluentes em cursos d'água, bem como a poluição hídrica gerada por esse setor. Considerando a importância dessa ação, este estudo objetivou avaliar o potencial de utilização de efluentes tratados provenientes de laticínios. Para tanto foram comparadas as características de efluentes produzidos em laticínios, em termos de potencial hidrogeniônico $(\mathrm{pH})$, demanda bioquímica de oxigênio $\left(\mathrm{DBO}_{5}\right)$, sólidos suspensos totais (SST), turbidez e coliformes termotolerantes, após serem submetidos a tratamentos, com os requisitos de qualidade presentes em normativas e resoluções nacionais e internacionais para o reúso industrial. A análise dos dados possibilitou verificar que entre os sistemas de tratamentos estudados a coagulação-floculação e biodegradação aeróbia; a coagulação, adsorção, separação por membrana e osmose reversa; o lodo ativado; a eletrocoagulação; e o biorreator por membrana e oxidação fotocatalítica (UV/ $\mathrm{H}_{2} \mathrm{O}_{2} / \mathrm{ZnO}$ ) permitiriam levar os efluentes à qualidade desejada para os parâmetros estudados, podendo esses estarem combinados ou não.

Palavras-chave: aproveitamento de efluentes; indústria de laticínios; tratamentos.

\section{ABSTRACT}

The reuse of water in industries has become a viable option to reduce the emission of effluents in watercourses, as well as water pollution generated by this sector. Considering the importance of this action, this study aimed to evaluate the potential of use treated effluents from dairies. For as much as, were compared the effluent characteristics produced in dairy industries, in terms of potential of Hydrogen $(\mathrm{pH})$, biological oxygen demand $\left(\mathrm{BOD}_{5}\right)$, total suspended solids (TSS), turbidity and fecal coliforms, after being treated, with the quality requirements found in national and international regulations for industrial reuse. The analysis of the data allowed to verify that among the treatments systems studied the coagulation-flocculation and aerobic biodegradation; coagulation, adsorption, membrane separation and reverse osmosis; activated sludge; electrocoagulation; membrane bioreactor and photocatalytic oxidation $\left(\mathrm{UV} / \mathrm{H}_{2} \mathrm{O}_{2} / \mathrm{ZnO}\right)$ allowed the effluent to be delivered to the desired quality, for the studied parameters, which could be combined or not.

Keyword: effluent use; dairy industry; treatments. 


\section{INTRODUÇÃO}

No Brasil a pecuária de leite e a indústria de laticínios são contribuintes essenciais para a nutrição humana e destacam-se por exercer um importante papel no desenvolvimento econômico do país. De acordo com a Companhia Nacional de Abastecimento - CONAB (2017), o país é o quinto maior produtor de leite no mundo, responsável por aproximadamente 34,6 biIhões de litros em 2016. Estima-se também que o consumo per capita nacional de leite tenha aumentado 4,64\% entre 2011 e 2016, evoluindo de 168,1 para 175,9 litros/per capita/ano (CONAB, 2017).

No entanto, os laticínios estão entre os setores alimentares que mais consomem água em seu processo de fabricação - entre 0,2 e 10,0 litros de água por litro de leite processado (QASIM \& MANE, 2013). Em consequência desse alto volume de água utilizado há a geração de elevada quantidade de efluentes, os quais são caracterizados por conterem altos teores de matéria orgânica e nutrientes (KUSHWAHA et al., 2010), além de gorduras e sólidos suspensos (FARIZOGLU; UZUNER, 2011). Essas águas residuárias são originadas essencialmente devido às perdas não acidentais de leite ou produtos lácteos em diferentes unidades de processamento, bem como a partir da limpeza e da lavagem de pisos e equipamentos (LATEEF et al., 2013) que carreiam os detritos de leite presente nesses locais, representando a principal fonte de poluição nessas indústrias, que, sem o cuidado adequado, caracterizam-se como potenciais riscos ambientais.

Como resposta às legislações ambientais e aos padrões de lançamentos de efluentes mais rigorosos (SUÁREZ et al., 2014), as indústrias passaram a buscar processos de produção mais eficientes e sustentáveis. Por conseguinte, a utilização de resíduos tratados vem se tornando uma opção econômica e ambientalmente viável, pois a adoção desta prática pode efetivamente reduzir os custos e a demanda por água e, em consequência, a quantidade de efluente gerado (KLEMES, 2012), resultando também na disponibilidade do volume economizado para fins mais nobres e na redu- ção dos impactos ambientais dos setores industriais. $\mathrm{Na}$ indústria, a água de reúso pode ser utilizada na limpeza de pisos e calçadas, bem como em diversas etapas do processo de produção, a exemplo: torres de resfriamento, condensadores, água de processos e alimentação de caldeira. Todavia, os sistemas de tratamento que visam essa prática devem garantir a remoção da carga poluente a um nível que seja compatível com as exigências de qualidade da água para o uso pretendido (QUAGLIA et al., 2013).

Embora essa reutilização na indústria de alimentos tenha sido limitada por muitos anos devido à restrição de regulamentos (CASANI et al., 2005), a Comissão Internacional do Codex Alimentarius (CODEX ALIMENTARIUS COMMISSION, 2001) surgiu para auxiliar essa prática por meio de um projeto com orientações sobre higiene para o reúso de água de processamento, na qual são incluídas definições, recomendações e exemplos de reúso de água. No entanto, para evitar o risco de contaminações nos laticínios, deve-se controlar o uso de efluentes tratados quando há a possibilidade de contato direto com a matéria-prima (ANDRADE, 2011), uma vez que a água usada na cadeia produtiva do leite, desde a ordenha do animal até a sanitização e manutenção dos equipamentos, tem influência direta sobre a inocuidade, qualidade e segurança dos produtos lácteos (KAMIYAMA \& OTENIO, 2013).

Nesse contexto é importante avaliar o cuidado a ser empregado de acordo com a qualidade do efluente a ser utilizado (DANTAS \& SALES, 2009), levando-se em consideração os critérios e padrões de exigência correspondentes à finalidade do reúso. Tendo em vista o volume de resíduos produzidos pelas indústrias de laticínios e, consequentemente, os impactos ambientais causados pelo lançamento deles nos corpos hídricos, este estudo teve como objetivo avaliar a viabilidade do aproveitamento de efluentes tratados oriundos de laticínios na própria indústria, com base nos regulamentos para o reúso industrial, nas características dos detritos e nos respectivos tratamentos.

\section{MATERIAIS E MÉTODOS}

No presente estudo foi empregado o método de revisão bibliográfica sistemática, considerando o tema utilização de efluentes tratados em indústrias de laticí- nios. Para tanto, foram empregadas as bases de dados da Coordenação de Aperfeiçoamento de Pessoal de Nível Superior (CAPES), Scientific Electronic Library Onli- 
ne (Scielo) e Science Direct. Na pesquisa, foram usados como palavras-chave os termos: indústria de laticínios, reúso e tratamento, nos idiomas português e inglês.

A análise do material reunido foi feita tendo em vista a caracterização dos efluentes em termos físico-químicos, os principais métodos utilizados no tratamento de resíduos líquidos provenientes de laticínios e as legislações e normativas usadas para implementação do reúso nesse setor. A partir dos dados levantados foi realizada uma avaliação do potencial de utilização do efluente tratado, considerando a qualidade mínima exigida por um processo, via legislações e normativas.

Os parâmetros empregados para avaliar essa possibilidade foram: potencial hidrogeniônico $(\mathrm{pH})$, demanda bioquímica de oxigênio - DBO (mg/L), sólidos suspensos totais - SST (mg/L), turbidez (NTU) e coliformes termotolerantes (NMP/100 mL). Quanto ao desempenho dos sistemas de tratamentos para efluentes de laticínios, verificou-se a taxa de remoção alcançada para os seguintes processos: coagulação-floculação e biodegradação aeróbia; coagulação e biodegradação aeróbia; coagulação e biorreator por membrana; coagulação, adsorção, separação por membrana e osmose reversa; reator descontínuo sequencial de biofilme; lodo ativado; reator em batelada com fase anaeróbia e aeróbia; processo de oxidação fotocatalítica; e eletrocoagulação.

Foram utilizadas também informações contidas em documentos normativos relacionados ao reúso industrial, a saber: Resolução $n^{\circ}$ 54/2005 do Conselho Nacional de Recursos Hídricos - CNRH (BRASIL, 2005), Norma Brasileira 13969 - NBR 13969 (ABNT, 1997), Regulamento Espanhol para Reúso de Água e o Real Decreto Espanhol no 1.620 (ESPANHA, 2007), Guia para Reúso de Água dos Estados Unidos (EPA, 2012), Guia de Reúso de Água para Empresas de Alimentos de Nova Gales do Sul (AUSTRÁLIA, 2008), Diretrizes Ambientais para o Uso da Água Reciclada da Tasmânia (AUSTRÁLIA, 2002) e o Código de Prática para o Uso de Água Recuperada da British Columbia (CANADÁ, 2013).

\section{RESULTADOS E DISCUSSÕES}

A escolha do tratamento adequado para efluentes provenientes de laticínios é realizada de acordo com as características desses e deve, também, atender aos requisitos de qualidade presentes em normas e diretrizes destinadas ao reúso industrial (Quadro 1). Embora a reutilização seja reconhecida como uma prática e coeficiente que contribui para a melhoria da gestão sustentável da água nas indústrias (SA-NGUANDUAN \& NITITVATTANANON, 2011), no Brasil, ainda não há regulamentos que definam parâmetros e restrições para o aproveitamento de efluentes tratados (CALHEIROS et al., 2010). No que se refere a regulamentos brasileiros, a Resolução n 54/2005 do CNRH (BRASIL, 2005) estabelece modalidades, diretrizes e critérios gerais para a prática de reúso não potável de água, todavia não define padrões de qualidade. Já a NBR 13969 (ABNT, 1997) dispõe sobre os requisitos de qualidade do efluente a ser aproveitado, porém somente para fins que exigem qualidade de água não potável; logo, regulamentos internacionais vêm sendo utilizados para suprir tal carência e auxiliar a implementação dessa prática no país.

Quando avaliados os efluentes provenientes de laticínios, a concentração e a composição podem variar significativamente dependendo do tipo de produto a ser fabricado, dos procedimentos operacionais usados no processamento de produtos à base de leite (RAD \& LEWIS, 2014), bem como do tamanho da planta industrial, do tipo de limpeza realizada no local e do volume de água utilizado no processo de fabricação da matéria-prima. Em geral, os efluentes de laticínios são caracterizados por conter elevadas concentrações, em especial de material orgânico, tais como: lactose, lipídios, caseína e outras proteínas (PASSEGGI et al., 2012), alto teor de DBO e demanda química de oxigênio (DQO), elevadas concentrações de sólidos em suspensão e óleos e graxas (FARIZOGLU; UZUNER, 2011). No entanto, quando se trata de reúso industrial, outros parâmetros também devem ser considerados, como pH, SST, turbidez e coliformes termotolerantes.

Quando analisado o pH das diferentes indústrias de laticínios (Tabela 1), é possível observar sua variação entre 3,3 e 7,5 (RIVAS et al., 2010; CHEN \& LIU, 2012; SIRIANUNTAPIBOON et al., 2005; SARKAR et al., 2006; ABREU et al., 2013; GERALDINO et al., 2015; PORWAL et al., 2015). Para esse parâmetro, são vários regulamentos e normativas que determinam limites. A norma brasileira NBR 13969 (ABNT, 1997) estabelece valo- 
res limites entre 6 e 8 visando à utilização do efluente tratado em lavagem de carros e outros usos que tenham contato direto com o usuário. O Guia para Reúso de Água dos Estados Unidos da América (resfriamento sem recirculação e torres de resfriamento) (EPA, 2012) e o Código de Prática para o Uso de Água Recuperada de British Columbia (torres de resfriamento, água de processo e alimentação de caldeira) (CANADÁ, 2013) estabelecem o mesmo valor limite (entre 6 e 9), entretanto para fins diferentes:

Quadro 1 - Especificações para o uso de efluente industrial de acordo com a finalidade.

\begin{tabular}{|c|c|c|}
\hline Usos finais & Requisitos de qualidade do efluente & Regulamentação/país \\
\hline $\begin{array}{l}\text { Lavagem de carros e outros } \\
\text { usos em que há contato direto } \\
\text { com o usuário }\end{array}$ & $\begin{array}{l}\mathrm{pH} \text { entre } 6 \text { e } 8 \text {; sólidos dissolvidos totais } \\
<200 \mathrm{mg} / \mathrm{L} \text {; turbidez < } 5 \mathrm{NTU} \text {; coliformes } \\
\text { termotolerantes }<200 \mathrm{NMP} / 100 \mathrm{~mL}\end{array}$ & NBR 13969 (1997)/Brasil \\
\hline $\begin{array}{l}\text { Lavagem de pisos e calçadas; } \\
\text { irrigação dos jardins; } \\
\text { manutenção dos lagos e canais } \\
\text { paisagísticos, exceto chafarizes }\end{array}$ & $\begin{array}{c}\text { turbidez }<5 \mathrm{NTU} \text {; coliformes } \\
\text { termotolerantes }<500 \mathrm{NMP} / 100 \mathrm{~mL}\end{array}$ & NBR 13969 (1997)/Brasil \\
\hline Descarga em vasos sanitários & $\begin{array}{l}\text { turbidez }<10 \mathrm{NTU} \text {; coliformes } \\
\text { termotolerantes }<500 \mathrm{NMP} / 100 \mathrm{~mL}\end{array}$ & NBR 13969 (1997)/Brasil \\
\hline $\begin{array}{l}\text { Processo e águas de lavagem } \\
\text { para a indústria de alimentos }\end{array}$ & sólidos suspensos totais $=35 \mathrm{mg} / \mathrm{L}$ & $\begin{array}{l}\text { Regulamentação Espanhola para } \\
\text { Reúso de Água - Real Decreto } 1.620 \\
\text { (ESPANHA, 2007)/Espanha }\end{array}$ \\
\hline $\begin{array}{l}\text { Torres de resfriamento e } \\
\text { condensadores }\end{array}$ & $\begin{array}{c}\text { sólidos suspensos totais = } 5 \mathrm{mg} / \mathrm{L} ; \\
\text { turbidez }=1 \mathrm{NTU}\end{array}$ & $\begin{array}{l}\text { Regulamentação Espanhola para } \\
\text { Reúso de Água - Real Decreto } 1.620 \\
\text { (ESPANHA, 2007)/Espanha }\end{array}$ \\
\hline Resfriamento sem recirculação & $\begin{array}{c}\text { pH entre } 6 \text { e } 9 ; \mathrm{DBO}_{5} \leq 30 \mathrm{mg} / \mathrm{L} \text {; sólidos } \\
\text { suspensos totais } \leq 30 \mathrm{mg} / \mathrm{L} ; \text { coliformes } \\
\text { termotolerantes } \leq 200 \mathrm{NMP} / 100 \mathrm{~mL}\end{array}$ & $\begin{array}{l}\text { Guia para Reúso de Água - EPA } \\
\text { (2012)/ Estados Unidos }\end{array}$ \\
\hline Torres de resfriamento & $\begin{array}{c}\text { pH entre } 6 \text { e } 9 ; \mathrm{DBO}_{5} \leq 30 \mathrm{mg} / \mathrm{L} \text {; sólidos } \\
\text { suspensos totais } \leq 30 \mathrm{mg} / \mathrm{L} ; \text { coliformes } \\
\text { termotolerantes } \leq 200 \mathrm{NMP} / 100 \mathrm{~mL}\end{array}$ & $\begin{array}{l}\text { Guia para Reúso de Água (EPA, } \\
\text { 2012)/Estados Unidos }\end{array}$ \\
\hline $\begin{array}{l}\text { Áreas de contato direto com } \\
\text { os alimentos ou superfícies de } \\
\text { contato com alimentos }\end{array}$ & $\begin{array}{c}\text { pH entre 6,5 e 8,5; turbidez < } 1 \text { NTU (95\%) } \\
<5 \text { NTU (máx.) }\end{array}$ & $\begin{array}{l}\text { Guia de Reúso de Água para } \\
\text { Empresas de Alimentos (AUSTRÁLIA, } \\
\text { 2008)/Austrália/Nova Gales do Sul }\end{array}$ \\
\hline Áreas de contato não alimentar & pH entre 6,5 e 8,5; turbidez < 5 NTU $(95 \%)$ & $\begin{array}{l}\text { Guia de Reúso de Água para } \\
\text { Empresas de Alimentos (AUSTRÁLIA, } \\
\text { 2008)/Austrália/Nova Gales do Sul }\end{array}$ \\
\hline $\begin{array}{l}\text { Processo industrial de sistema } \\
\text { aberto (com possível contato } \\
\text { humano) }\end{array}$ & $\begin{array}{c}\mathrm{pH} \text { entre } 5,5 \text { e } 8,0 ; \mathrm{DBO}_{5}<50 \mathrm{mg} / \mathrm{L} ; \\
\text { coliformes termotolerantes }<100 \\
\mathrm{NMP} / 100 \mathrm{~mL}\end{array}$ & $\begin{array}{c}\text { Diretrizes Ambientais para o Uso da } \\
\text { Água Reciclada (AUSTRÁLIA, 2002)/ } \\
\text { Austrália/Tasmânia }\end{array}$ \\
\hline $\begin{array}{l}\text { Processo industrial de sistema } \\
\text { fechado (sem contato humano) }\end{array}$ & $\begin{array}{c}\mathrm{pH} \text { entre } 5,5 \text { e } 8,0 ; \mathrm{DBO}_{5}<80 \mathrm{mg} / \mathrm{L} ; \\
\text { coliformes termotolerantes }<10.000 \\
\mathrm{NMP} / 100 \mathrm{~mL}\end{array}$ & $\begin{array}{c}\text { Diretrizes Ambientais para o Uso da } \\
\text { Água Reciclada (AUSTRÁLIA, 2002)/ } \\
\text { Austrália/Tasmânia }\end{array}$ \\
\hline $\begin{array}{l}\text { Torres de resfriamento, água } \\
\text { de processo e alimentação de } \\
\text { caldeira }\end{array}$ & $\begin{array}{c}\mathrm{pH} \text { entre } 6 \text { e } 9 ; \mathrm{DBO}_{5} \leq 45 \mathrm{mg} / \mathrm{L} \text {; sólidos } \\
\text { suspensos totais } \leq 45 \mathrm{mg} / \mathrm{L} \text {; coliformes } \\
\text { termotolerantes }<200 \mathrm{NMP} / 100 \mathrm{~mL}\end{array}$ & $\begin{array}{l}\text { Código de Prática para o Uso de } \\
\text { Água Recuperada (CANADÁ, 2013)/ } \\
\text { Canadá/British Columbia }\end{array}$ \\
\hline
\end{tabular}

$\mathrm{DBO}_{5}$ : demanda bioquímica de oxigênio; $\mathrm{pH}$ : potencial hidrogeniônico. 
- resfriamento sem recirculação e torres de resfriamento;

- torres de resfriamento, água de processo e alimentação de caldeira.

Já as Diretrizes Ambientais para o Uso da Água Reciclada da Tasmânia (AUSTRÁLIA, 2002) estabelecem limites menores para o $\mathrm{pH}$ (entre 5,5 e 8,0), tendo em vista a reutilização no processo industrial com possível contato humano.

Para o teor de matéria orgânica dos efluentes de laticínios estudados (Tabela 1), em termos de $\mathrm{DBO}_{5}$ verifica-se um amplo intervalo entre as concentrações de 475 a 14.800 mg/L (RIVAS et al., 2010; RIVAS et al., 2011; SIRIANUNTAPIBOON et al., 2005; SARKAR et al., 2006; BERNAL et al., 2008; ABREU et al., 2013; GERALDINO et al., 2015; PORWAL et al., 2015). Essa variação ocorre devido ao tipo de processamento e produto final (KARADAG et al., 2015), sendo o conteúdo de lactose e gordura o principal responsável por sua formação (CARVALHO et al., 2013). Sobre o aproveitamento do efluente industrial, a NBR 13969 (ABNT, 1997) não esta- belece limites para as concentrações de matéria orgânica $\left(\mathrm{DBO}_{5}\right)$. Porém, a legislação norte-americana (EPA, 2012) sugere que a $\mathrm{DBO}_{5}$ seja $\leq 30 \mathrm{mg} / \mathrm{L}$ para os dois tipos de reúso especificados pelo guia, a saber: resfriamento sem recirculação e torres de resfriamento. Já na regulamentação de British Columbia (CANADÁ, 2013) é recomendada concentração $\leq 45 \mathrm{mg} / \mathrm{L}$ para reúso em torres de resfriamento, água de processo e alimentação de caldeira. Para a utilização do efluente no processo industrial de sistema fechado (sem contato humano) a concentração de $\mathrm{DBO}_{5}$ deve ser $<80 \mathrm{mg} / \mathrm{L}$, de acordo com as diretrizes da Tasmânia (AUSTRÁLIA, 2002).

Para os SST relatam-se concentrações entre 124,29 e 3.317,00 mg/L (RIVAS et al., 2010; SARKAR et al., 2006; BERNAL et al., 2008; PORWAL et al., 2015) (Tabela 1). Se considerada a utilização de efluente, a norma brasileira (NBR 13969 -ABNT, 1997) também não estabelece requisitos de qualidade para os SST. No entanto, a U.S. Environmental Protection Agency - USEPA (EPA, 2012) recomenda concentração máxima de $30 \mathrm{mg} / \mathrm{L}$ para este parâmetro, visando o reúso em torres de resfriamento, enquanto no Código de Prática para o Uso de Água Recuperadada British Columbia (CANADÁ, 2013),

Tabela 1 - Características dos efluentes provenientes de laticínios.

\begin{tabular}{|c|c|c|c|c|c|c|}
\hline Produto final & pH & $\begin{array}{l}\mathrm{DBO}_{5} \\
(\mathrm{mg} / \mathrm{L})\end{array}$ & $\begin{array}{c}\text { SST } \\
(\mathrm{mg} / \mathrm{L})\end{array}$ & $\begin{array}{l}\text { Turbidez } \\
\text { (NTU) }\end{array}$ & $\begin{array}{l}\text { Coliformes } \\
\text { termotolerantes } \\
\text { (NMP/100 mL) }\end{array}$ & Referências \\
\hline Queijo & 4,23 & 6.342 & 3.317 & 1.557 & ND & Rivas et al. (2010) \\
\hline Queijo & ND & 14.800 & ND & 1.331 & ND & Rivas et al. (2011) \\
\hline Leite e sorvete & $6,07-7,10$ & ND & ND & 145 & ND & Chen \& Liu (2012) \\
\hline $\begin{array}{l}\text { Leite e } \\
\text { produtos lácteos }\end{array}$ & 6 & 4.000 & ND & ND & ND & $\begin{array}{l}\text { Sirianuntapiboon et al. } \\
\text { (2005) }\end{array}$ \\
\hline $\begin{array}{l}\text { Leite e } \\
\text { produtos lácteos }\end{array}$ & $5,5-7,5$ & 475 & 425 & 22,5 & ND & Sarkar et al. (2006) \\
\hline $\begin{array}{l}\text { Leite e } \\
\text { produtos lácteos }\end{array}$ & ND & 620,33 & 124,29 & 194 & $2,9 E+09$ & Bernal et al. (2008) \\
\hline $\begin{array}{l}\text { Leite e } \\
\text { produtos lácteos }\end{array}$ & 5,56 & 825 & ND & ND & $1,4 \mathrm{E}+03$ & Abreu et al. (2013) \\
\hline $\begin{array}{l}\text { Leite e } \\
\text { produtos lácteos }\end{array}$ & 3,3 & 4.670 & ND & 1.347 & ND & Geraldino et al. (2015) \\
\hline $\begin{array}{l}\text { Leite e } \\
\text { produtos lácteos }\end{array}$ & 5,73 & 1.010 & 1470,7 & 1049,4 & ND & Porwal et al. (2015) \\
\hline
\end{tabular}

pH: potencial hidrogeniônico; DBO $_{5}$ : demanda bioquímica de oxigênio; SST: sólidos suspensos totais; ND: não disponível. 
a concentração não deve ser maior do que $44 \mathrm{mg} / \mathrm{L}$. Já o limite determinado pelo regulamento espanhol (Real Decreto $n=1.620$ - ESPANHA, 2007) para a mesma finalidade é ainda menor ( $5 \mathrm{mg} / \mathrm{L}$ ).

Quanto à turbidez, os valores encontrados nos estudos variaram entre 22,5 e $1.557,0$ NTU (Tabela 1) (RIVAS et al., 2010; RIVAS et al., 2011; CHEN \& LIU, 2012; SARKAR et al., 2006; BERNAL et al., 2008; GERALDINO et al., 2015; PORWAL et al., 2015). Segundo a NBR 13969 (ABNT, 1997) a concentração desse parâmetro no efluente deve ser menor que 5 NTU para seu aproveitamento em lavagem de carros e outros usos com contato direto com o usuário, e menor que 10 NTU para descarga em vasos sanitários. O Guia de Reúso de Água para Empresas de Alimentos de Nova Gales do Sul (AUSTRÁLIA, 2008) também sugere que a turbidez seja menor que $5 \mathrm{NTU}$, porém para o uso em áreas de contato direto com os alimentos ou superfícies de contato com alimentos. A menor concentração de turbidez (1 NTU) requerida entre os regulamentos está presente na normativa espanhola (ESPANHA, 2007), que visa à utilização do efluente em torres de resfriamento e condensadores.

Quanto aos coliformes termotolerantes (Tabela 1 ), foi constatada concentração mínima de 1,4 E+03 $\mathrm{NMP} / 100 \mathrm{~mL}$ e máxima de 2,9 E+09 NMP/100 mL nos efluentes de indústrias de leite e derivados (ABREU et al., 2013; BERNAL et al., 2008). A NBR 13969 (ABNT, 1997) recomenda que a concentração de coliformes termotolerantes seja menor que $200 \mathrm{NMP} / 100 \mathrm{~mL}$ para utilização em lavagem de veículos e outras práticas que necessitem de contato direto com o indivíduo. A legislação da British Columbia (CANADÁ, 2013) indica o mesmo valor de concentração, porém para o uso em torres de resfriamento, alimentação de caldeira e água de processo. Já para a regulamentação da Tasmânia (AUSTRÁLIA, 2002), a concentração de coliformes termotolerantes deve ser menor do que $10.000 \mathrm{NMP} / 100 \mathrm{~mL}$ para o aproveitamento do efluente no processo industrial de sistema fechado (sem contato humano).

Por meio da caracterização do efluente, pode-se verificar que em algumas indústrias os valores encontrados de pH estão dentro dos padrões presentes nas normativas que visam sua utilização. No entanto, quando analisados os demais parâmetros ( $\mathrm{DBO}_{5}$, SST, turbidez e coliformes termotolerantes), verifica-se que eles se encontram acima dos limites estabelecidos pelos regulamentos, de maneira que, quando pretendido o reúso industrial, há a necessidade de submeter os efluentes gerados a tratamentos que empreguem tecnologias capazes de ajustar o $\mathrm{pH}$ e remover os demais poluentes, às concentrações estabelecidas pelas normativas e resoluções.

Em razão da concentração e do volume dos despejos industriais variarem amplamente, dependendo dos processos de fabricação empregados e dos métodos de controle dos despejos (MENDES et al., 2004), a caracterização de resíduos se torna uma tarefa básica para o equacionamento adequado do problema de tratamento, pois a partir dessas informações podem ser adotados métodos de tratamentos físicos, químicos ou biológicos, que sejam eficientes na remoção dos poluentes presentes nos efluentes de laticínios.

Para redução de $\mathrm{DBO}_{5}$ e $\mathrm{DQO}$ existem várias tecnologias possíveis. Rivas et al. (2010), ao empregarem o processo de coagulação-floculação seguido de biodegradação aeróbia em uma indústria de queijo, atingiram uma remoção de até $60 \%$. Como coagulante foi adotado o $\mathrm{FeSO}_{4}$, que apresentou maior eficiência quando comparado aos demais coagulantes usados no estudo $\left(\mathrm{Al}_{2}(-\right.$ $\left.\mathrm{SO}_{4}\right)_{3}$ e $\mathrm{FeCl}_{3}$ ). Após essa etapa, o efluente passou por tratamento aeróbio, para alcançar maior redução da matéria orgânica (99\% de $\mathrm{DBO}_{5}$ e $96 \%$ de DQO). Rivas et al. (2011) realizaram um estudo utilizando $\mathrm{NaOH}$ e $\mathrm{CaOH}_{2}$ como coagulantes no tratamento de efluente semelhante e obtiveram resultados similares aos anteriores, alcançando uma remoção de $50 \%$ de $\mathrm{DBO}_{5} \mathrm{e}$ DQO. Para obter maior remoção da matéria orgânica, o efluente foi submetido a um tratamento biológico aeróbio, obtendo remoção final de $96 \%$ de $\mathrm{DBO}_{5}$.

O processo de coagulação também foi empregado como pré-tratamento em efluentes de produtos como leite e sorvete, Chen e Liu (2012) obtiveram uma redução de $98,95 \%$ de turbidez usando o coagulante PAC (hidroxicloreto de alumínio). Os autores Sarkar et al. (2006) avaliaram a eficiência da coagulação e da adsorção, e os resultados mostraram que a partir da combinação dessas duas tecnologias foi possível reduzir $57 \%$ dos sólidos dissolvidos totais e $62 \%$ de DQO. O efluente pré-tratado foi submetido à osmose reversa, alcançando redução de $98 \%$ na DQO. Formentini-Schmitt et al. (2013) obtiveram uma remoção de 93,3\% de turbidez por meio da coagulação, floculação e sedimentação 
(CFS) para esses efluentes. No entanto, esse processo não foi eficiente na remoção de DQO $(39,4 \%)$, justificando a necessidade de um tratamento subsequente (ultrafiltração direta).

Quando se trata de remoção de matéria orgânica, o tratamento físico-químico não é um processo eficiente para atender aos padrões preconizados pelas normativas (para os parâmetros $\mathrm{DBO}_{5}$ e DQO presentes no efluente de laticínios, em razão da elevada carga). No entanto, o tratamento biológico deve atender alguns aspectos importantes, tais como a remoção da matéria orgânica e a estabilidade de compostos químicos orgânicos de difícil degradação. Existe ainda a possibilidade de redução da matéria orgânica em até 99\%, quando se empregam reatores aeróbios e a ultrafiltração (FARIZOGLU; UZUNER, 2011). Andrade et al. (2013) analisaram também a aplicabilidade de um biorreator aeróbio de membrana e alcançaram a eficiência de remoção de $99 \%$ para DQO.

Outros sistemas de tratamento, como lodo ativado, também foram empregados para a remoção de matéria orgânica, alcançando a remoção de $95 \%$ de $\mathrm{DBO}_{5}$ (LATEEF et al., 2013). E quando esse sistema de tratamento foi associado à filtração, a redução foi de $85,15 \%$ de $\mathrm{DBO}_{5}$, e ainda $99,54 \%$ de SST e $99,79 \%$ de turbidez (PORWAL et al., 2015). Reatores descontínuos sequenciais de biofilme também se apresentam como uma alternativa, promovendo a remoção de $89 \%$ de DQO, $83 \%$ de $\mathrm{DBO}_{5}$, e ainda $82 \%$ de óleo e graxa (SIRIANUNTAPIBOON et al., 2005).

Além dos processos aeróbios, os anaeróbios provaram também ser eficientes para tratamento de efluentes lácteos (OMIL et al., 2003). A exemplo, empregando-se reatores anaeróbios de batelada sequencial é possível alcançar uma remoção de DQO de 92,8\% (SANTANA et al., 2016). O filtro anaeróbio também é uma tecnologia utilizada, conseguindo remover entre 80 e $90 \%$ de DQO (GANNOUN et al., 2008). Há, ainda, tratamentos que empregam tanto um sistema quanto outro e a taxa de remoção pode ser aumentada. Reatores em batelada com fases anaeróbia e aeróbia alcançaram a remoção de $88,6 \%$ para sólidos dissolvidos totais, $91,4 \%$ para turbidez, $97,3 \%$ para $\mathrm{DBO}_{5}$ e $99,9 \%$ para os coliformes termotolerantes (BERNAL et al.,2008).

Há também outros processos não convencionais, como nanofiltração (NF), microfiltração, ultrafiltração, osmose reversa e eletrocoagulação, que vêm sendo utilizados no tratamento de efluentes industriais, em especial os da indústria de laticínios, objetivando produzir resíduos com qualidade que não somente atenda aos padrões de lançamento, mas também permita o seu reúso. Biorreatores por membrana (MBR), seguidos de NF, mostraram uma eficiência de $99,9 \%$ para remoção de DQO e de $93,1 \%$ para remoção de sólidos totais (ANDRADE et al., 2014). A partir dessa remoção, o efluente tratado final cumpre as normas exigidas para sua reutilização, na refrigeração e na geração de vapores, podendo ainda ser reusado para a lavagem de pisos, áreas externas e caminhões. Processos de eletrocoagulação também foram empregados e as taxas de remoção alcançadas foram de $99,98 \%$ para a turbidez, $94,90 \%$ para a cor, e $96,36 \%$ para a DQO. E quando empregado o processo de oxidação fotocatalítica (UV/ $\mathrm{H}_{2} \mathrm{O}_{2} / \mathrm{ZnO}$ ), a remoção alcançada foi de $100 \%$ para o parâmetro coliformes termotolerantes (GERALDINO et al., 2015).

Esses tratamentos, além de oferecerem eficiência na remoção de parâmetros determinantes para o lançamento em corpos hídricos, podem também produzir efluentes de excelente qualidade para o reúso nas indústrias de laticínios. Outras vantagens podem ser obtidas com o seu uso, como a operação contínua e o reduzido uso de substâncias químicas. O Quadro 2 apresenta o desempenho dos sistemas de tratamento dos efluentes analisados neste estudo, composto pelos parâmetros presentes nas legislações pertinentes ao reúso industrial.

\section{Potencial de aproveitamento industrial de efluentes provenientes de laticínios}

A avaliação do potencial de utilização dos efluentes de laticínios foi realizada comparando-se as características desses, após o tratamento, com os requisitos de qualidade estabelecidos em regulamentos específicos. Ao avaliar o $\mathrm{pH}$ dos efluentes estudados pelos autores Rivas et al. (2010), Sarkar et al. (2006),
Porwal et al. (2015) e Geraldino et al. (2015), foi possível verificar que os valores encontrados para este parâmetro estão de acordo com os requisitos preconizados na normativa brasileira (ABNT, 1997), nos regulamentos norte-americano (EPA, 2012) e canadense (CANADÁ, 2013), no Guia de Reúso de Nova 
Gales do Sul (AUSTRÁLIA, 2008) e na legislação da Tasmânia (AUSTRÁLIA, 2002) (Figura 1).

Em relação à remoção da DBO (Figura 2), o sistema de tratamento composto por coagulação-floculação e biodegradação aeróbia conseguiu reduzir a $\mathrm{DBO}_{5}$ para $63,42 \mathrm{mg} / \mathrm{L}$ (RIVAS et al., 2010), quantidade suficiente para atender aos requisitos para utilização em processo em que não haja contato humano exigidos na legislação da Tasmânia (AUSTRÁLIA, 2002). Já os efluentes que foram submetidos aos tratamentos compostos por coagulação, adsorção, separação por membrana e osmose reversa (SARKAR et al., 2006) e reator em batelada com fases anaeróbia e aeróbia (BERNAL etal., 2008) reduziram a concentração de $\mathrm{DBO}_{5}$ do efluente para 9,50 e $16,75 \mathrm{mg} / \mathrm{L}$, respectivamente. Por meio dos tratamentos foi possível atender aos requisitos de qualidade presentes nos regulamentos dos Estados Unidos (EPA, 2012), da Tasmânia (AUSTRÁLIA, 2002) e da British Columbia (CANADÁ, 2013). Em contrapartida, os efluentes estudados por Rivas et al. (2011), Sirianuntapiboon et al. (2005) e Porwal et al. (2015) apresentaram concentrações de $\mathrm{DBO}_{5}$ pós-tratamento de 592 , 440 e $150 \mathrm{mg} / \mathrm{L}$, respectivamente, e não atenderam aos limites indicados para esse parâmetro.

Em relação à concentração de SST, a partir do tratamento composto por reator em batelada com fases anaeróbia e aeróbia (BERNAL et al., 2008) e por lodo ativado (PORWAL et al., 2015), as concentrações passaram de 124,29 para $14,17 \mathrm{mg} / \mathrm{L}$ e de $1.470,70$ para $6,77 \mathrm{mg} / \mathrm{L}$, respectivamente (Figura 3). Esses resultados foram suficientes para aten-

\section{Quadro 2 - Desempenho dos sistemas de tratamento para efluentes em indústrias de laticínios.}

\begin{tabular}{|c|c|c|c|c|}
\hline $\begin{array}{l}\text { Origem do } \\
\text { efluente final }\end{array}$ & Sistema de tratamento & Remoção (\%) & $\begin{array}{l}\text { pH após } \\
\text { tratamento }\end{array}$ & Referência \\
\hline Queijo & $\begin{array}{l}\text { Coagulação-floculação e } \\
\text { biodegradação aeróbia }\end{array}$ & $\begin{array}{c}\mathrm{DBO}_{5}: 99 \\
\text { Turbidez: } 99\end{array}$ & 7,6 & Rivas et al. (2010) \\
\hline Queijo & $\begin{array}{c}\text { Coagulação e biodegradação } \\
\text { aeróbia }\end{array}$ & $\mathrm{DBO}_{5}: 96$ & ND & Rivas et al. (2011) \\
\hline Leite e sorvete & $\begin{array}{c}\text { Coagulação e biorreator por } \\
\text { membrana }\end{array}$ & Turbidez: 98 e 95 & ND & Chen \& Liu (2012) \\
\hline $\begin{array}{l}\text { Leite e produtos } \\
\text { lácteos }\end{array}$ & $\begin{array}{l}\text { Reator descontínuo } \\
\text { sequencial de biofilme }\end{array}$ & $\mathrm{DBO}_{5}: 89$ & ND & $\begin{array}{l}\text { Sirianuntapiboon } \\
\text { et al. (2005) }\end{array}$ \\
\hline $\begin{array}{l}\text { Leite e produtos } \\
\text { lácteos }\end{array}$ & $\begin{array}{c}\text { Coagulação, adsorção, } \\
\text { separação por membrana e } \\
\text { osmose reversa }\end{array}$ & $\begin{array}{c}\mathrm{DBO}_{5}: 98 \\
\text { SST: } 100 \\
\text { Turbidez: } 100\end{array}$ & 6,55 & Sarkar et al. (2006) \\
\hline $\begin{array}{l}\text { Leite e produtos } \\
\text { lácteos }\end{array}$ & $\begin{array}{l}\text { Reator em batelada com } \\
\text { fases anaeróbia e aeróbia }\end{array}$ & $\begin{array}{c}\text { DBO }_{5}: 97,3 \\
\text { SST: } 88,6 \\
\text { Turbidez: } 91,4 \\
\text { Coliformes } \\
\text { termotolerantes: } 99,9\end{array}$ & ND & Bernal et al. (2008) \\
\hline $\begin{array}{l}\text { Leite e produtos } \\
\text { lácteos }\end{array}$ & $\begin{array}{l}\text { Processo de oxidação } \\
\text { fotocatalítica }\left(\mathrm{UV} / \mathrm{H}_{2} \mathrm{O}_{2} / \mathrm{ZnO}\right)\end{array}$ & $\begin{array}{c}\text { Coliformes } \\
\text { termotolerantes: } 100\end{array}$ & ND & Abreu et al. (2013) \\
\hline $\begin{array}{l}\text { Leite e produtos } \\
\text { lácteos }\end{array}$ & Eletrocoagulação & Turbidez: 99,98 & 7,35 & $\begin{array}{l}\text { Geraldino et al. } \\
\qquad(2015)\end{array}$ \\
\hline $\begin{array}{l}\text { Leite e produtos } \\
\text { lácteos }\end{array}$ & Lodo ativado & $\begin{array}{c}\mathrm{DBO}_{5}: 85,15 \\
\text { SST: } 99,54 \\
\text { Turbidez: } 99,79\end{array}$ & 7,22 & Porwal et al. (2015) \\
\hline
\end{tabular}

$\mathrm{DBO}_{5}$ : demanda bioquímica de oxigênio; SST: sólidos suspensos totais; ND: não disponível; pH: potencial hidrogeniônico. Os valores estão expressos em $\mathrm{mg} / \mathrm{L}$ - exceto turbidez (NTU) e coliformes termotolerantes (NMP/100 mL). 


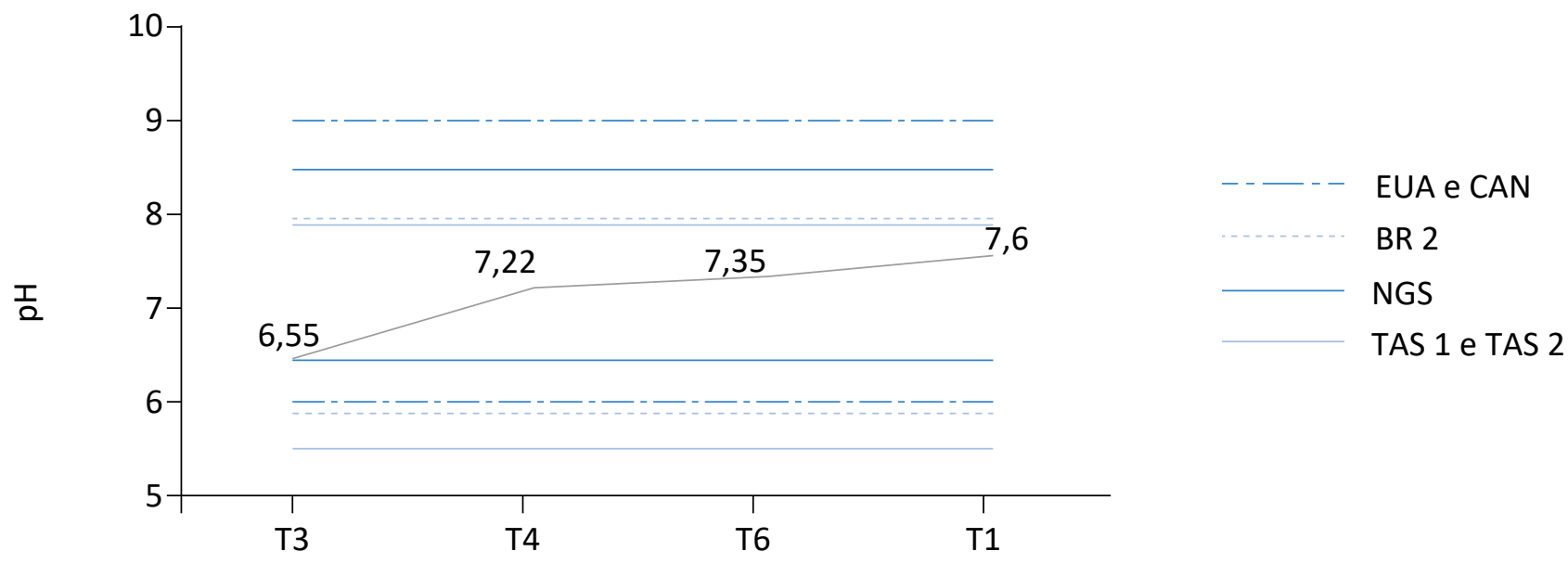

pH: potencial hidrogeniônico; EUA: limite indicado pela normativa norte-americana; CAN: limite sugerido pela normativa canadense; BR: limite sugerido pelo regulamento brasileiro; NGS: limite preconizado pela normativa de Nova Gales do Sul; TAS 1: limite recomendado pela normativa da Tasmânia para reúso em processo fechado; TAS 2: limite requerido pela normativa da Tasmânia para reúso em processo aberto.

Figura 1 - Valores de pH alcançados quando submetidos aos tratamentos de coagulação, adsorção, separação por membrana e osmose reversa (T3); lodo ativado (T4); eletrocoagulação (T6) e coagulação-floculação e biodegradação aeróbia (T1), atendendo aos padrões das normativas norte-americana e canadense e aos regulamentos de Nova Gales do Sul, brasileiro e da Tasmânia para reúso em processo fechado e em processo aberto.

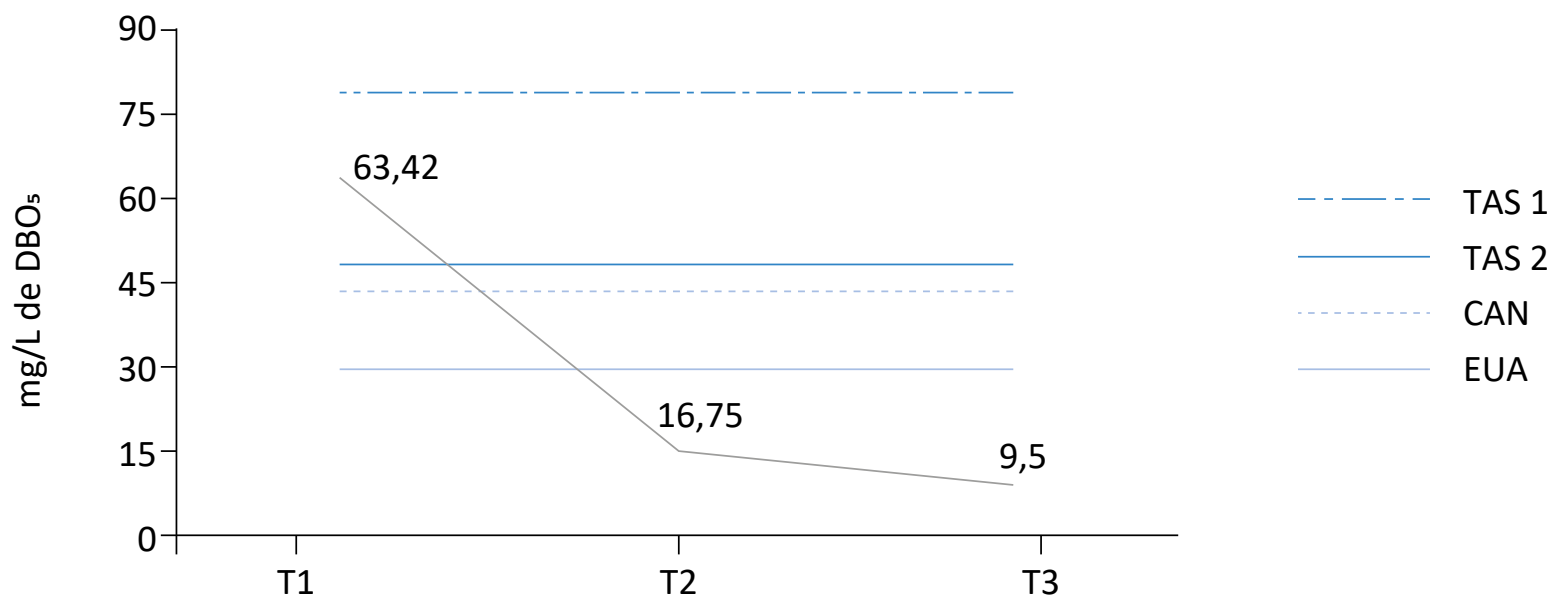

$\mathrm{DBO}_{5}$ : demanda bioquímica de oxigênio; TAS 1: limite preconizado pela normativa da Tasmânia para reúso em processo fechado; TAS 2: limite requerido pela normativa da Tasmânia para reúso em processo aberto; CAN: limite sugerido pela normativa canadense; EUA: limite estabelecido pela normativa norte-americana.

Figura 2 - Níveis de remoção alcançados para o parâmetro demanda bioquímica de oxigênio empregando-se a coagulação-floculação e biodegradação aeróbia (T1); o reator em batelada com fases anaeróbia e aeróbia (T2); e a coagulação, adsorção, separação por membrana e osmose reversa (T3), e que atenderam as concentrações limites estabelecidas pelas normativas da Tasmânia para reúso em processo fechado e para reúso em processo aberto; e pelos regulamentos canadense e norte-americano. 
der ao determinado pelo regulamento espanhol (Real Decreto no 1.620, ESPANHA, 2007) - exceto para o uso em torres de resfriamento e condensadores, que estabelece o limite de $5 \mathrm{mg} / \mathrm{L}$ - , pelo Guia para Reúso de Água dos Estados Unidos (EPA, 2012) e pelo Código de Prática para o Uso de Água Recuperada da British Columbia (CANADÁ, 2013). O tratamento empregado por Sarkar et al. (2006), que consistiu em coagulação, adsorção, separação por membrana e osmose reversa, obteve a remoção de $100 \%$ dos SST, atendendo aos padrões de qualidade de todos os regulamentos citados neste estudo (Figura 3 ).

Quanto à turbidez dos efluentes de laticínios, pesquisas demonstraram que é possível alcançar concentrações reduzidas, de 1,52 NTU (CHEN \& LIU, 2012) e de 2,20 NTU (PORWAL et al., 2015), empregando a coagulação (Figura 4). Esses valores atendem aos padrões determinados pela NBR 13969 (ABNT, 1997) e pelo Guia de Reúso de Água para Empresas de Alimento de Nova Gales do Sul (AUSTRÁLIA, 2008). Os efluentes submetidos ao processo de coagulação, adsorção, separação por membrana e osmose reversa e eletrocoagulação alcançaram remoção de $100 \%$, ou aproximadamente, da turbidez (SARKAR et al., 2006; GERALDINO et al., 2015), atendendo aos regulamentos de Nova Gales do
Sul (NGS) (AUSTRÁLIA, 2008) e do Brasil (ABNT, 1997), além do espanhol (Real Decreto № 1.620 - ESPANHA, 2007). Por outro lado, os tratamentos empregados por Rivas et al. (2010) e Bernal et al. (2008) não alcançaram nenhum dos padrões exigidos para esse parâmetro (15,57 e 16,70 NTU, respectivamente).

Ao analisar a concentração de coliformes termotolerantes $(2,9 \mathrm{E}+06 \mathrm{MNP} / 100 \mathrm{~mL})$ detectada após tratamento (Figura 5) foi constado que não houve atendimento a nenhum limite indicado para este parâmetro (BERNAL et al., 2008) pelos regulamentos de reúso industrial. Em contrapartida, o efluente tratado pelo processo de oxidação fotocatalítica (UV/ $\mathrm{H}_{2} \mathrm{O}_{2} / \mathrm{ZnO}$ ) obteve $100 \%$ de remoção de coliformes termotolerantes (ABREU et al., 2013), atendendo a norma brasileira (NBR 13969 - ABNT, 1997) e os regulamentos australiano (AUSTRÁLIA, 2002), canadense (CANADÁ, 2013) e norte-americano (EPA, 2012).

Estudos mostram que alguns tratamentos não foram eficientes no que diz respeito ao atendimento dos requisitos de qualidade presentes nas legislações de reúso industrial. No entanto, há tecnologias capazes de alcançar os padrões de qualidade exigidos para sua utilização mesmo que os efluentes possuam altas concentrações de poluentes.

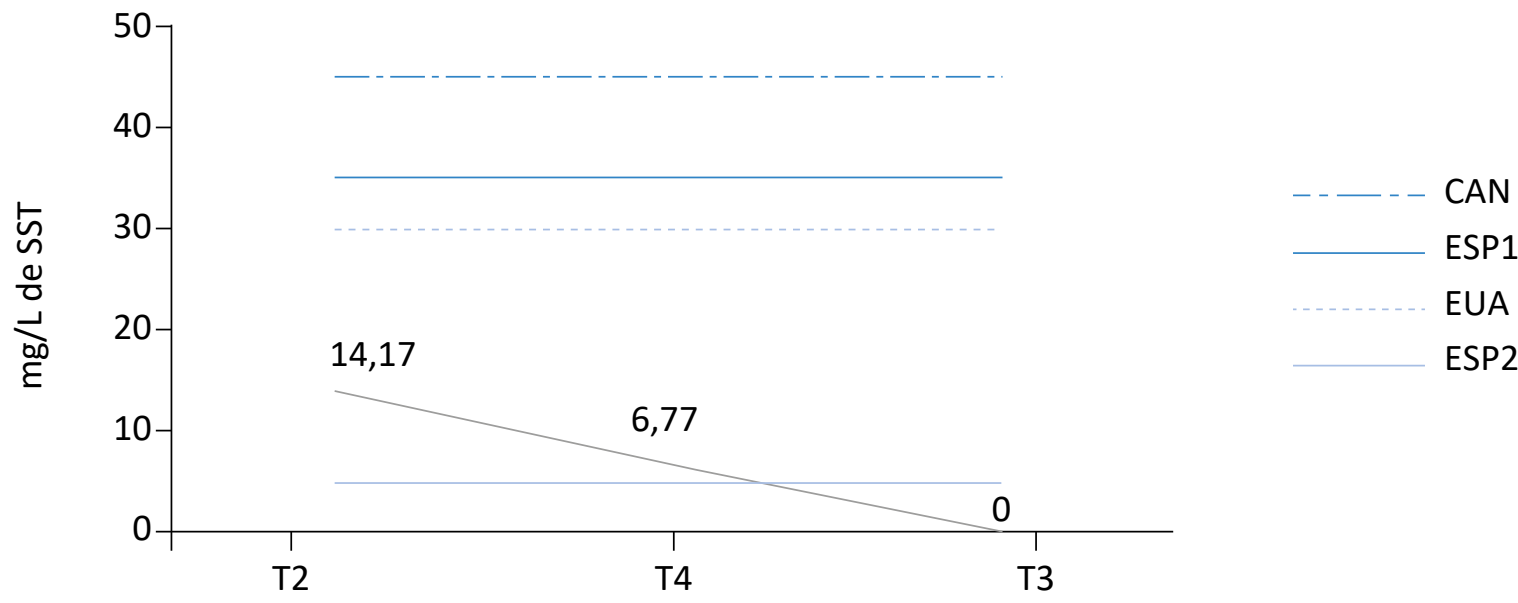

SST: sólidos suspensos totais; CAN: limite indicado pela normativa canadense; EUA: limite preconizado pela normativa norte-americana; ESP 1: limite indicado pela regulamentação espanhola para águas de lavagem; ESP 2: limite preconizado pela normativa espanhola para reúso em torres de resfriamento e condensadores.

Figura 3 - Taxas de remoção para os sólidos suspensos totais em efluentes de laticínios quando empregados os seguintes tratamentos: reator em batelada com fases anaeróbia e aeróbia (T2); lodo ativado (T4); coagulação, adsorção, separação por membrana e osmose reversa (T3) e atendimento ao preconizado pelos regulamentos do Canadá, da Espanha e dos Estados Unidos (EUA). 


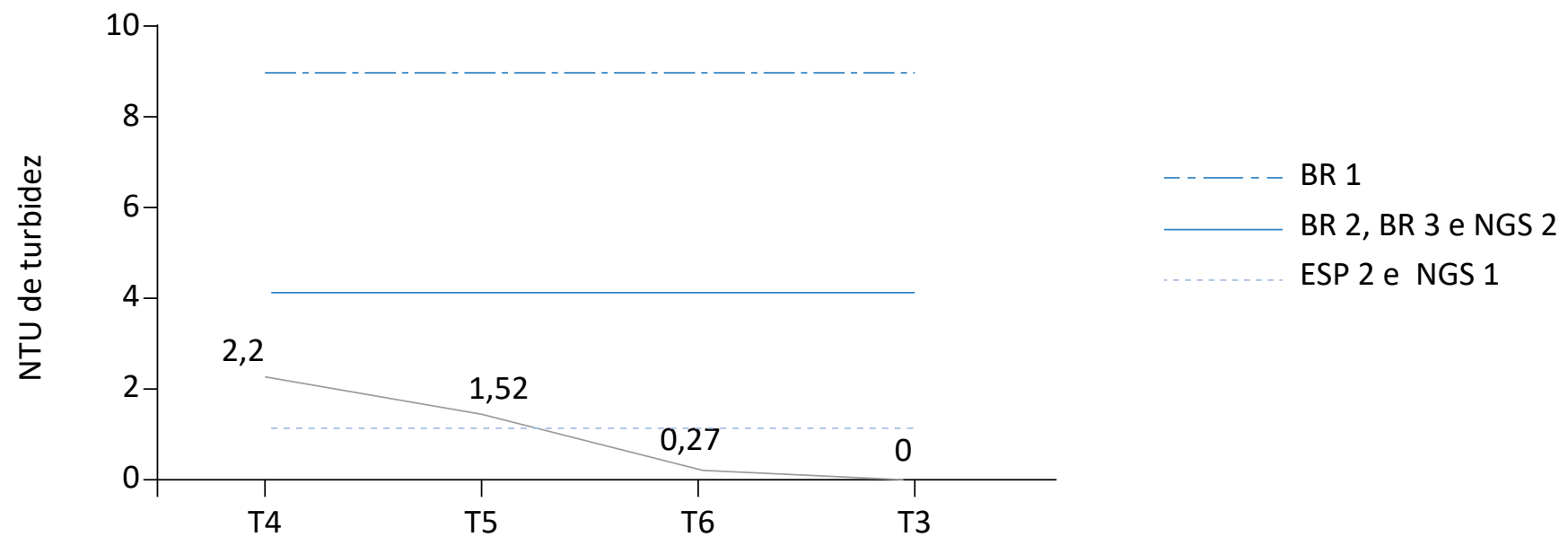

BR 1: limite requerido pela norma brasileira para fins de descarga em vasos sanitários; BR 2: limite recomendado pela norma brasileira para lavagem de carros e outras práticas com contato direto com o usuário; BR 3: limite indicado pela normativa brasileira para lavagem de pisos e calçadas, irrigação dos jardins, manutenção dos lagos e canais paisagísticos; NGS 2: limite preconizado pela normativa australiana para utilização em áreas de contato não alimentar; NGS 1: limite preconizado pela normativa australiana para utilização em áreas de contato não alimentar; ESP 2: limite preconizado pela normativa espanhola para reúso em torres de resfriamento e condensadores.

Figura 4 - Concentrações de turbidez encontradas em efluentes de laticínio submetidos aos tratamentos de lodo ativado (T4); coagulação e biorreator por membrana (T5); eletrocoagulação (T6); e coagulação, adsorção, separação por membrana e osmose reversa (T3). Os valores encontrados atenderam as resoluções brasileira e australiana.

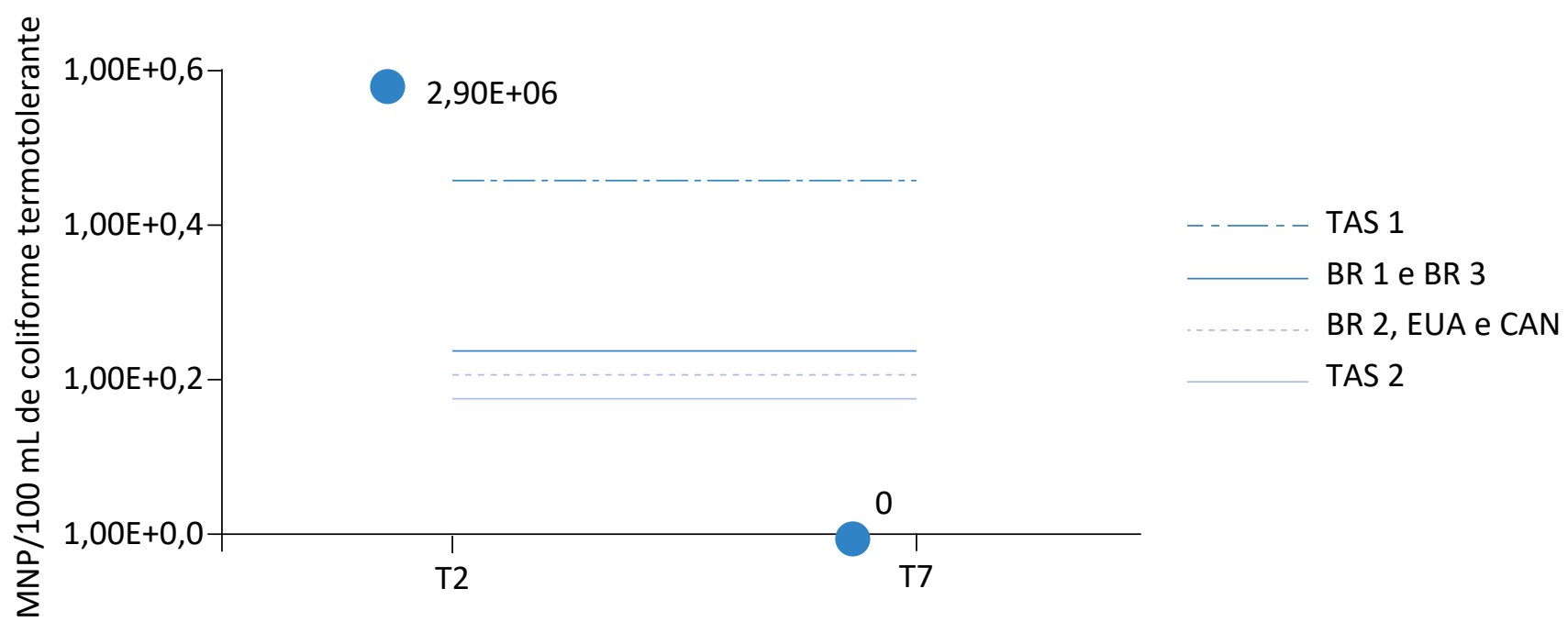

TAS 1: limite preconizado pela normativa da Tasmânia para reúso em processo fechado; BR 1: limite requerido pela normativa brasileira para fins de descarga em vasos sanitários; BR 3: limite indicado pela normativa brasileira para lavagem de pisos e calçadas, irrigação dos jardins, manutenção dos lagos e canais paisagísticos; BR 2: limite recomendado para lavagem de veículos e outros usos com contato direto com o usuário; EUA: limite estabelecido pela normativa norte-americana; CAN: limite sugerido pela normativa canadense; TAS 2: limite requerido pela normativa da Tasmânia para reúso em processo aberto.

Figura 5 - Concentração de coliformes termotolerantes em efluentes de laticínios pós-tratamento empregando-se processo de reator em batelada com fases anaeróbia e aeróbia (T2) e quando submetido à oxidação fotocatalítica (UV/ $\mathrm{H}_{2} \mathrm{O}_{2} / \mathrm{ZnO}$ ) (T7). No segundo caso, atendeu a todas as normativas (da Tasmânia, do Brasil, dos Estados Unidos e do Canadá); no primeiro caso, por sua vez, a remoção alcançada não atendeu a nenhuma das normas ou regulamentos para reúso industrial. 


\section{CONCLUSÕES}

A característica do efluente nas indústrias de laticínios pode variar dependendo do produto final a ser obtido, assim como das tecnologias empregadas no processamento da matéria-prima. A partir dessa caracterização é possível escolher técnicas de tratamentos capazes de alcançar os padrões de qualidade exigidos nos regulamentos para o reúso industrial. Embora os efluentes dessas indústrias apresentem concentrações físico-químicas variadas, eles possuem potenciais de utilização após a aplicação de tratamentos capazes de ajustar o $\mathrm{pH}$ e remover a DBO $(\mathrm{mg} / \mathrm{L})$, os SST $(\mathrm{mg} / \mathrm{L})$, a turbidez (NTU) e os coliformes termotolerantes (NMP/100 mL).
Entre os tratamentos estudados, os que atenderam as normativas empregadas, em termos de $\mathrm{pH}$, foram: coagulação-floculação e biodegradação aeróbia; coagulação, adsorção, separação por membrana e osmose reversa; lodo ativado; e eletrocoagulação. No que diz respeito à $\mathrm{DBO}_{5}$, os tratamentos mais adequados foram: coagulação-floculação e biodegradação; e coagulação e biorreator por membrana. Em relação aos SST e à turbidez, o sistema de tratamento foi coagulação, adsorção, separação por membrana e osmose reversa. Já para os coliformes termotolerantes o mais indicado foi o de oxidação fotocatalítica (UV/ $\mathrm{H}_{2} \mathrm{O}_{2} / \mathrm{ZnO}$ ).

\section{AGRADECIMENTOS}

Os autores agradecem ao Conselho Nacional de Desenvolvimento Científico e Tecnológico (CNPQ) pelo fi- nanciamento do projeto (processo: 407728 / 2012-0) e

pela bolsa de produtividade (Processo 312697/2014-7)

\section{REFERÊNCIAS}

ABREU, P.; PEREIRA, E. L.; CAMPOS, C. M. M.; NAVES, L. N. Photocatalytic oxidation process $\left(U V / \mathrm{H}_{2} \mathrm{O}_{2} / \mathrm{ZnO}\right)$ in the treatment and sterilization of dairy wastewater. Acta Scientiarum, v. 35, p. 75-81, jan.-mar. 2013.

ANDRADE, L. H. Tratamento de efluente de indústria de laticínios por duas configurações de biorreator com membranas e nanofiltração visando o reuso. 231f. Dissertação (Mestrado em Saneamento, Meio Ambiente e Recursos Hídricos) Universidade Federal de Minas Gerais, Belo Horizonte, 2011.

ANDRADE, L. H.; MENDES, F. D. S.; ESPÍNDOLA, J. C.; AMARAL, M. C. S. Nanofiltration as tertiary treatment for the reuse of dairy wastewater treated by membrane bioreactor. Separation and Purification Technology, v. 126, p. 21-29, abr. 2014.

ANDRADE, L. H.; MOTTA, G. E.; AMARAL, M. C. S. Treatment of dairy wastewater with a membrane bioreactor. Brazilian Journal of Chemical Engineering, v. 30, p. 759-770, out.-dez. 2013.

ASSOCIAÇÃO BRASILEIRA DE NORMAS TÉCNICAS (ABNT). NBR 13969: tanque sépticos: unidades de tratamento complementar e disposição final dos efluentes - Projeto, construção e operação. Rio de Janeiro: ABNT, 1997.

AUSTRÁLIA. Environmental Guidelines for the Use of Recycled Water in Tasmania. Austrália: Environment Division/ Department of Primary Industries, Water and Environment, 2002.

. Water reuse guideline for food businesses in NSW considering reusing water. Austrália: NSW Food Authority, 2008.

BERNAL, C. B.; VÁZQUEZ, G.; QUINTAL, I. B.; BUSSY, A. L. Microalgal Dynamics in Batch Reactors for Municipal Wastewater Treatment Containing Dairy Sewage Water. Water Air Soil Pollutant, v. 190, p. 259-270, 2008.

BRASIL. Resolução no 54, de 28 de novembro de 2005. Estabelece modalidades, diretrizes e critérios gerais para a prática de reúso direto não potável de água, e dá outras providências. Diário Oficial da União, Brasília, nov. 2005. 
CALHEIROS, C. A.; SOUZA, V. R.; MENEZES, C. C.; CARNEIRO, J. D. S.; RAMOS, T. M. Gestão de qualidade em pequenas empresas processadoras de leite: situação atual e recomendações. Revista do Instituto de Laticínios Cândido Tostes, v. 65, p. 17-25, 2010.

CANADÁ. Reclaimed Water Guideline: a Companion Document to the Municipal Wastewater Regulation Made Under the Environmental Management Act. Canadá: B.C. Ministry of Environment, 2013.

CARVALHO, F.; PRAZERES, A. R.; RIVAS, J. Cheese whey wastewater: characterization and treatment. Science of the Total Environment, v. 445-446, p. 385-396, 2013.

CASANI, S.; ROUHANY, M.; KNØCHEL, M. A discussion paper on challenges and limitations to water reuse and hygiene in the food industry. Water Research, v. 39, p. 1134-1146, mar. 2005.

CHEN, W.; LIU, J. The possibility and applicability of coagulation-MBR hybrid system in reclamation of dairy wastewater. Desalination, v. 285, p. 226-231, jan. 2012.

CODEX ALIMENTARIUS COMMISSION. Codex Committee on Food Hygiene. Proposed draft guidelines for the hygienic reuse of processing water in food plants. Joint FAO/WHO Food Standards Programme, 34th Session. Bangkok, Thailand: Codex Alimentarius Commission, 2001.

COMPANHIA NACIONAL DE ABASTECIMENTO (CONAB). Perspectivas para a agropecuária, Brasília, v. 5, 2017.

DANTAS, D. L.; SALES, A. W. C. Aspectos ambientais, sociais e jurídicos do reúso da água. Revista de Gestão Social e Ambiental, v. 3, p. 4-19, set.-dez. 2009.

ENVIRONMENTAL PROTECTION AGENCY (EPA). Guidelines for Water Reuse. Washington, D.C.: EPA, 2012.

ESPANHA. Spanish Regulations for Water Reuse: Royal Decree 1620/2007 of 7 December. Catalunha: Universidade Politécnica da Catalunha, 2007.

FARIZOGLU, B.; UZUNER, S. The investigation of dairy industry wastewater treatment in a biological highperformance membrane system. Biochemical Engineering Journal, v. 57, p. 46-54, out. 2011.

FORMENTINI-SCHMITT, D. M.; ALVES, Á. C. D.; VEIT, M. T.; BERGAMASCO, R.; VIEIRA, A. M. S.; FAGUNDES-KLEN, M. R. Ultrafiltration combined with coagulation/flocculation/sedimentation using Moringaoleifera as coagulant to treat dairy industry wastewater. Water Air Soil Pollution, v. 224, p. 1-15, ago. 2013.

GANNOUN, H.; KHELIFI, E.; BOUALLAQUI, H.; TOUHAMI, Y.; HAMDI, M. Ecological clarification of cheese whey prior to anaerobic digestion in upflow anaerobic filter. Bioresource Technology, v. 99, p. 6105-6111, jan. 2008.

GERALDINO, H. C. L.; SIMIONATO, J. I.; FREITAS, T. K. F. S.; GARCIA, J. C.; CARVALHO JÚNIOR, O.; CORRER, C. J. Efficiency and operating cost of electrocoagulation system applied to the treatment of dairy industry wastewater. Acta Scientiarum Technology, v. 37, p. 401-408, 2015.

KAMIYAMA, C. M.; OTENIO, M. E. Aspectos sobre qualidade da água e qualidade de produtos na indústria de laticínios. Revista Instituto de Laticínios Cândido Tostes, v. 68, p. 42-50, mar.-abr. 2013.

KARADAG, D.; KÖROG LU, O. M.; OZKAYA, B.; CAKMAKCI, M. A review on anaerobic biofilm reactors for the treatment of dairy industry wastewater. Process Biochemistry, v. 50, p. 262-271, fev. 2015.

KLEMES, J. J. Industrial water recycle/reuse. Current Opinion in Chemical Engineering, v. 1, p. 238-245, ago. 2012.

KUSHWAHA, J. P.; SRIVASTAVA, V. C.; MALL, I. D. Organics removal from dairy wastewater by electrochemical treatment and residue disposal. Separation and Purification Technology, v. 76, p. 198-205, dez. 2010. 
LATEEF, A.; CHAUDHRY, M. N.; ILYAS, S. Biological treatment of dairy wastewater using activated sludge. Science Asia, v. 39, p. 179-185, 2013.

MENDES, A. A.; CASTRO, H. F.; PEREIRA, E. B.; JÚNIOR; A. F. Aplicação de lipases no tratamento de águas residuárias com elevados teores de lipídeos. Química Nova, v. 28, p. 296-305, 2005.

OMIL, F.; GARRIDO, J. M.; ARROJO, B.; MÉNDEZ, R. Anaerobic filter reactor performance for the treatment of complex dairy wastewater at industrial scale. Water Research, v. 37, p. 4099-4108, 2003.

PASSEGGI, M.; LÓPEZ, I.; BORZACCONI, L. Modified UASB reactor for dairy industry wastewater: performance indicators and comparison with the traditional approach. Journal of Cleaner Production, v. 26, p. 90-94, 2012.

PORWAL, H. J.; MANE, A. V.; VELHAL, S. G. Biodegradation of dairy effluent by using microbial isolates obtained from activated sludge. Water Resources and Industry, v. 9, p. 1-15, 2015.

QASIM, O.; MANE, A. V. Characterization and treatment of selected food industrial effluents by coagulation and adsorption techniques. Water Resources and Industry, v. 4, p. 1-12, dez. 2013.

QUAGLIA, A.; PENNATI, A.; BOGATAJ, M.; KRAVANJA, Z.; SIN, G.; GANI, R. Industrial process water treatment and reuse: a framework for synthesis and design. Industrial \& Engineering Chemistry Research, v. 53, p. 5160-5171, ago. 2013.

RAD, S. J.; LEWIS, J. M. Water utilisation, energy utilisation and waste water management in the dairy industry: a review. International Journal of Dairy Technology, v. 67, 2014.

RIVAS, J.; PRAZERES, A. R.; CARVALHO, F. Aerobic biodegradation of precoagulated cheese whey wastewater. Journal of Agricultural and Food Chemistry, v. 59, p. 2511-2517, fev. 2011.

RIVAS, J.; PRAZERES, A. R.; CARVALHO, F.; BELTRÁN, F. Treatment of Cheese Whey Wastewater: Combined CoagulationFlocculation and Aerobic Biodegradation. Journal Agricultural and Food Chemistry, v. 58, p. 7871-7877, 2010.

SA-NGUANDUAN, N.; NITITVATTANANON, V. Strategic decision making for urban water reuse application: a case from Thailand. Desalination, v. 268, p. 141-149, 2011.

SANTANA, R. S. S.; PRETTI, A. A.; MORENO, J. G.; DACANAL, G. C.; TOMMASO, G.; RIBEIRO, R. Effect of biomass configuration on the behavior of pilot-scale anaerobic batch reactors treating dairy wastewater. International Biodeterioration \& Biodegr adation, v. 106, p. 80-87, jan. 2016.

SARKAR, B.; CHAKRABARTI, P. P.; VIJAYKUMAR, A.; KALE, V. Wastewater treatment in dairy industries: possibility of reuse. Desalination, v. 195, p. 141-152, 2006.

SIRIANUNTAPIBOON, S.; JEEYACHOK, N.; LARPLAI, R. Sequencing batch reactor biofilm system for treatment of milk industry wastewater. Journal of Environmental Management, v. 76, p. 177-183, abr. 2005.

SUÁREZ, A.; FIDALGO, T.; RIERA, F. A. Recovery of dairy industry wastewaters by reverse osmosis. Production of boiler water. Separation and Purification Technology, v. 133, p. 204-211, set. 2014.

SUÁREZ, A.; RIERA, F. A. Production of high-quality water by reverse osmosis of milk dairy condensates. Journal of Industrial and Engineering Chemistry, v. 21, p. 1340-1349, 2015. 